\title{
Literary Salons Across Britain and Ireland in the Long Eighteenth Century
}

Review Number: 1897

Publish date: Thursday, 25 February, 2016

Author: Amy Prendergast

ISBN: 9781137512703

Date of Publication: 2015

Price: $£ 55.00$

Pages: 250pp.

Publisher: Palgrave Macmillan

Publisher url: https://www.palgrave.com/page/detail/literary-salons-across-britain-and-ireland-in-the-long-eighteen century-/?isb=9781137512703

Place of Publication: London

Reviewer: Rachel Wilson

In this engaging book, Amy Prendergast focuses primarily on the period between 1750 and the 1820 s and seeks to provide 'the first detailed examination of the literary salon in Ireland, considered in the wider contexts of contemporary salon culture in Britain and France' as well as a study of the 'cultural transfers' between these salons (p. 1). As this overview suggests, Prendergast is primarily concerned with Ireland, though England and France maintain a strong presence throughout, usually through the eyes of Irish travellers and exiles and those with what we would now refer to as dual nationality (normally Anglo-Irish in this case). This Irish focus makes a welcome addition to the pre-existing bodies of work on literary salons and elite women in the 18th century, both of which remain underdeveloped for the Emerald Isle, especially when compared to the much more substantial historiography available for England and Scotland. Prendergast's work not only helps to fill the void, but will hopefully encourage further research.(1) The book's back cover also promises an 'interdisciplinary emphasis' and this too is delivered, the author having woven together the intersecting threads of male and female, history and literature, elite and bourgeoisie to produce a monograph which will be of use to scholars of early modern women's history, social and gender history and literature studies.

The book's thematic scope is impressive, taking in several distinct types of salon including the Bluestocking model in operation from roughly the 1750s and the single-author salons of the later 18th century.

Bluestockings (a term coined to describe intellectual men and more particularly women) hosted salons which promoted the work of their guests and assisted new authors in attaining recognition. By contrast, Prendergast explains, single-author salons were much more focused on the literary outputs of their hostesses, though they also made time for the work of other published authors (p. 140). Other salons fell into neither category, having no Bluestocking connections, yet a broader reach than single-author gatherings (pp. 66-71).

The six chapters are organised along predominantly geographical lines. Chapter one favours France and argues for the importance of salon culture to the French Enlightenment and for the spread of this culture to Britain and Ireland via early modern tourists. Chapter two compares the salons of France and Britain and in so doing uncovers many instances of reciprocity between the two, though the author contends that overall 
the French system was 'emulated and adapted, rather than simply adopted' by the British (p. 50). This chapter is also where the book's only real discussion of Scotland occurs, with a section devoted to the salons of Edinburgh in which Prendergast rejects the idea that 'Scotland and the Scottish Enlightenment were untouched by salon culture' (p. 46), though she does believe that Scottish salons appeared later than those in England and offered 'significantly less support for published female authors' (p. 71). The third chapter utilises a case-study approach taking as its primary focus Elizabeth Vesey and her salons in England and Ireland, while also branching out to look at other women who shuttled between the two countries, such as Anne Dawson, née Fermor and Anne Donnellan. Prendergast here argues for the importance of cultural exchanges between salons, especially with regards to the Anglo-Irish Bluestockings, whose bi-nationality was enhanced by their place 'as "importers" or cultural intermediaries for these exchanges' (p. 101). Chapter four zooms in on the Irish salon of Elizabeth Rawdon, the English-born countess of Moira and a woman named by Prendergast as 'one of the only rivals for the title of Ireland's most important salon hostess during Vesey's period of influence' (pp. 83-4). As well as discussing the countess's own publications and the help she gave to other female writers, Prendergast also shows the heavy emphasis Moira's salon placed upon Irish 'antiquarianism' (that is the study of 'the language, customs, and cultures of ancient Ireland') and 'associational antiquarianism' (p. 112). In chapter five, single-author salons take centre stage as the author shifts the focus to provincial rather than urban salons and once again moves between Ireland and England to look at gatherings hosted by women, including Maria Edgeworth and the less familiar and underappreciated Anna Miller. The book then finishes with a chapter which stays predominantly with Ireland, but which breaks with the format used elsewhere by examining other forms of entertainment favoured by the elite, such as private theatrical performances and reading groups, rather than salons. This section is interesting in its own right and complements recent research undertaken on domestic theatrical productions in Ireland by scholars such as Patricia McCarthy, but given its very different focus compared to the rest of the book, it may have worked better as an independent article. $(2)$

While certain similarities and variations between salons can be assumed, such as the differences between the Bluestocking, non-Bluestocking and single-author templates which are implied by their different names, Prendergast's multi-national approach facilitates a deeper discussion of other, less obvious parallels and differences which only a comparative study can uncover. Having explained that salons were predominantly hosted by women (known as salonnières in France and simply as salon hostesses in England, Scotland and Ireland), she then draws out the varying approaches each group took to their duties. The salonnières, it emerges, were hyper-competitive and waspish, catering to an almost exclusively male guest list and enduring an 'antithetical relationship' with each other. Their British and Irish neighbours, however, preferred to create 'a distinctly collaborative network' and welcomed a gender neutral company (p. 50). This modus operandi remained in force until the early 19th century, when it became more common in newly formed British salons to have 'a central female hostess surrounded by male participants' (p. 71). In reflecting further upon who was admitted, Prendergast also argues for a kind of limited meritocracy, if such a phrase can be allowed, which extended across Ireland, Britain and France. Participants were typically drawn from the middling and upper orders, but at the lower end of this spectrum in particular, only those with true ability were welcomed, though some still suffered from feelings of inadequacy when faced with their more famous salon companions (p. 88). For those aspiring writers, male or female, who were fortunate enough to make the cut, salons (barring single-author gatherings) were an invaluable source of patrons and patronesses and a place where unpublished work was circulated, critiqued and edited, thus providing 'a professional network and ultimately an influential audience' for such writers (p. 102). For female participants and the hostess, a further benefit was the rare opportunity salons presented for them to engage in 'associational life', an idea which is frequently reiterated throughout the book and juxtaposed against the many additional forms of 'associational' sociability available to men, such as coffee houses and contemporary clubs and societies (pp. 2-3). Indeed Prendergast blames the advent of the coffee house for the long absence of English literary salons between the Civil War and the mid-18th century (p. 45).

The methodological difficulties caused by the 'largely oral nature' (p. 9) of the salons might have been a cause for concern, however Prendergast addresses the issue early on and any worries about the limitations of 
studying a predominantly verbal phenomenon soon fade away. Using an impressive array of sources, including correspondence, household account books and inventories, works published by salon participants (particularly dedications to salon hostesses) and descriptions of paintings of specific gatherings, the book reconstructs the layout, guest lists and feel of the salons under consideration and leaves the reader with a clear idea of how an evening there would have looked and sounded. The survival of the pre-salon notes (or contemporary copies of these notes) of French salonnières have even allowed the author to extrapolate the behind-the-scenes planning undertaken by hostesses and recover conversations long since passed (p. 19). There are also accounts of the layout and interior decoration of houses, such as Elizabeth Vesey's home at Lucan House and a fascinating study of the irregular seating plans Vesey employed to keep her gatherings from becoming stale. As a side note, architectural and American history buffs will enjoy learning that Lucan's oval room was likely the inspiration for the Oval Office in the White House (pp. 81, 87).

I consider it a compliment to say that while the book has taught me a great deal about early modern salons, it has also left me wanting to learn more. In particular, two brief mentions of male salon hosts piqued my curiosity, all the more so because they date from the less well-explored first half of the 18th century. These were the Jacobite 2nd Duke of Ormond, in exile in France from 1715 until his death in 1745 (pp. 28-9), and Dean Patrick Delany, referred to in an endnote for chapter three (p. 195). Were there other male salon hosts in any of the countries under discussion, I wonder, and how did the gender of a host or hostess affect the look and feel of a salon? The prevalence of political salons during this period and the ever increasing historiography dedicated to this phenomenon also left me musing on the political benefits of being either the hostess of a literary salon, or her spouse.(3) Politics and salons are mentioned in passing during the book, especially in relation to Lady Moira and Elizabeth Vesey, the latter of whom, Prendergast notes, welcomed members of Ireland's political class into her home. It remains to be seen, however, whether literary salons were ever created with any kind of political agenda in mind, even if it was secondary to academic pursuits.

As with all works, there are some quibbles, but none serious enough to detract from the quality of the book. Its geographical and chronological parameters do not strictly follow its title and the omission of any reference to France in this is particularly curious, given that the title of Prendergast's Ph.D. thesis, upon which this work is based, does mention it. The concern is that this issue might cause the book to be overlooked by those researching French salons, when in fact they would benefit from reading it. The book would also have been strengthened by the inclusion of some additional historical context to facilitate a deeper understanding of how the salons were affected by the world around them and to help orientate the non-specialist reader. Only one short paragraph in the introduction attempts to do this, and it is essentially a list of major Irish, British and French events between 1688 and the 1840s (p. 10). Other discussions of, or references to, events such as the 1798 Rebellion and the French Revolution are fleeting, though they succeed in showing that such crises deeply affected and even tore apart the lives of salon hostesses and participants and demanded that the salon adapt to survive into the 19th century (pp. 168-9). The author is to be commended for taking the time to update her bibliography to reflect some of the newer publications in the field, rather than relying solely on the research already done for her Ph.D., and throughout the book she shows a strong grasp of the historiography relevant to her topic, which, given the large temporal and geographical sweep of her work, is no mean feat. Nonetheless, there are occasional places where a greater discussion of the relevant historiography would have been useful. In particular the terms 'public' and 'private' are used several times (for instance pp. 23 and 153) with only limited engagement with the sizable body of work which has been published on these themes. Many of the relevant items do appear in the notes and bibliography, however, suggesting that Prendergast is aware of them, but was constrained by the limits of space from going into more detail.(4) 
In terms of presentation and style, the book is well written and should be accessible to the lay reader as well as the professional historian. Rather than assuming knowledge, Prendergast is considerate of her audience when it comes to new concepts and terminology, taking the time to explain ideas which the non-specialist may be unfamiliar with. Certain allowances have been made to balance the competing demands of the scholarly and non-scholarly markets, but such is the case with most works nowadays. The index is fairly short, at six and a half pages, but this will be of little consequence to the non-academic reader. The use of endnotes over footnotes will displease some scholars, especially as these notes contain a considerable amount of information, but again this layout will suit a general audience (though some may tire during the early chapters of flicking to the back of the book to look up the translations for the numerous French passages). The translations themselves, though, which were done primarily by Prendergast herself, are very well executed, no doubt due to her background studying the language.

To conclude, this book has much to recommend it. It is a most enjoyable and at times thought-provoking read, whose comparative approach gives it an edge and a freshness while allowing it to advance the historiography of literary salons in Ireland, England and France and pave the way for future research. On the basis of this, her first monograph, I look forward to reading Dr Prendergast's future work.

\section{Notes}

1. For instance see Susan Schmid, British Literary Salons of the Late Eighteenth and Early Nineteenth Centuries (London, 2013); Readers, Writers, Salonnie?res: Female Networks in Europe, 1700-1900, ed. Hillary Brown and Gillian Dow (Oxford, 2011); Amanda Vickery, The Gentleman's Daughter: Women's Lives in Georgian England (London, 2006); Katharine Glover, Elite Women and Polite Society in Eighteenth Century Scotland (Woodbridge, 2011). Back to (1)

2. Patricia McCarthy 'Private theatricals in Irish houses, 1730 to 1815' Irish Architectural and Decorative Studies, 14 (2013), 12-49.Back to (2)

3. On political salons, see for instance Women in British Politics, 1760-1860: the Power of the Petticoat, ed. Kathryn Gleadle and Sarah Richardson (London, 2000). Back to (3)

4. See, for example, Shifting the Boundaries: Transformations of the Languages of Public and Private in the Eighteenth Century, ed. Dario Castiglione and Lesley Sharpe (Exeter, 1995); Joan Landes, 'The public and the private sphere: a feminist reconsideration' in Feminists Read Habermas: Gendering the Subject of Discourse, ed. Johanna Meehan (New York, NY, 1995), pp. 91-116. Back to (4)

Source URL:https://reviews.history.ac.uk/review/1897

\section{Links}

[1] https://reviews.history.ac.uk/item/147167 